\title{
NOTICING HYBRID RECASTS IN TEXT CHAT
}

\author{
Mark J. Oliver \\ British Council, Singapore \\ Email: Markjoliver78@gmail.com
}

APA Citation: Oliver, M. J. (2016). Noticing hybrid recasts in text chat. English Review: Journal of English Education, 5(1), 25-36

Received: 14-10-2016

Accepted: 09-11-2016

Published: 01-12-2016

\begin{abstract}
This study examined ten EFL learners' noticing of the corrective nature of a form of text-based SCMC (text chat) feedback that combined a recast of a grammatical error with metalinguistic information. The feedback, termed a hybrid recast, was provided by a nativespeaker interlocutor during two text chat activities: a spot-the-difference and pictureordering task. Data was collected in two ways: analysis of task-based dyadic text chat interaction in which uptake was used as an indicator of learner noticing, and a post-task questionnaire containing questions that identified evidence of learner noticing. Interaction analysis showed that learners responded to almost two thirds of the hybrid recasts with uptake. In addition, every learner provided evidence that they had correctly perceived at least some of the hybrid recasts as corrective in their post-task questionnaire responses.

Keywords: Text chat (text-based SCMC - synchronous computed-mediated communication), Corrective feedback, Negative evidence, Recasts, Hybrid recasts, Metalinguistic correction, Uptake, Repair, Noticing
\end{abstract}

\section{INTRODUCTION}

This study builds on the body of face-to-face and text chat studies of learner noticing of recasts. The purpose of the current study was to explore whether the corrective nature of recasts in text chat could be made more salient to learners by adapting them to include metalinguistic information in a form of feedback I termed 'Hybrid recast'. Up to this point only one study by Sheen (2007) had investigated such a form of feedback and this was conducted in a face-to-face environment.

Recasts have been repeatedly shown to be the most commonly used form of feedback by language teachers (Lyster \& Ranta, 1997; Lyster \& Mori, 2006), especially in response to grammatical errors (Mackey et al., 2000). However, despite this popularity, a significant amount of research (Lyster \&
Ranta, 1997; Mackey et al., 2000) points to recasts being less effective than more explicit forms of feedback, such as metalinguistic feedback. A common argument against their effectiveness is that they frequently fail to be perceived as corrective by learners. This is especially the case when the linguistic focus of the recasts is grammar (Lyster 1998; Mackey et al., 2000; Sheen, 2006).

A number of studies (Doughty \& Varela, 1998; Loewen \& Philip, 2006; Sheen, 2006) have investigated whether certain characteristics of recasts resulted in greater learner noticing. Loewen and Philip (2006) and Sheen (2006) found that recasts that were segmented, stressed and declarative, and therefore more explicit, were more likely to be perceived as corrective. Sheen (2007) interestingly found that a form of feedback combining a recast with metalinguistic information, 
termed metalinguistic correction, led to more $\mathrm{L} 2$ gains than traditional recasts.

In recent years there has been a growing interest in the utilization of textbased SCMC or text chat in language learning (Simpson 2002, p. 414). There is significant evidence (Kung, 2004; Lai \& Zhao, 2006; Pellettieri, 2000, p. 81; Smith, 2004; Smith \& Sauro, 2009) that communication via text chat can increase learner noticing of both language and interactional feedback for three reasons: firstly, turn-taking proceeds at a slower speed; secondly, the language is written and thus more salient; thirdly, the enduring nature of the text chat means learners can reread previous messages, notice inconsistencies in their target language output and self-correct. However, despite of these benefits, when studies (Lai \& Zhao, 2006; Sauro, 2009) measured learner noticing of recasts provided via text chat, they reported a similar failure of learners to perceive recasts as corrective. This study attempts to investigate whether learners noticed the corrective nature of a form of feedback based on Sheen's (2007) metalinguistic correction which combined a recast of a grammatical error with a brief piece of metalinguistic information.

Interaction researchers, such as Long (1996), have viewed noticing as an essential liaison that connects interactional input and learner output (Egi, 2010). When considering learner noticing of recasts we must look at a number of issues that remain under debate. Firstly, there is some debate as to whether recasts provide negative or positive evidence. Secondly, while some view recasts as a form of implicit feedback, others see them as explicit feedback. Thirdly, there are conflicting views regarding the uptake that recasts can trigger (Ellis \& Sheen, 2006).
Ellis and Sheen (2006, p. 585) define positive evidence as samples of grammatical and acceptable L2 and negative evidence as information about language which is not grammatical or acceptable. The developmental benefits of recasts are most widely held (Long, 1996; Oliver, 1995) to lie in negative evidence, which encourages the two types of noticing that Schmidt (1990) argued were prerequisites for L2 acquisition. Firstly, the linguistic feature being recast is made more salient to the learner and secondly, recasts prompt learners to compare their erroneous utterance with the recast allowing them to 'notice the gap' (Schmidt \& Frota, 1986). However, Bao et al. (2011) state that this argument rests on the assumption that learners are able to recognize the corrective intent of recasts. There is significant evidence that recasts, especially of grammatical errors, are often not perceived as corrective (Lyster, 1998b; Mackey et al., 2000; Nicholas et al., 2001). Interactionally, recasts can perform the function of acknowledging the content of the preceding turn (Nicholas et al, 2001).

In Long's (1996) definition, recasts are viewed as an implicit form of feedback where errors are implied and the focus is on meaning not form. However, others (Ellis \& Sheen, 2006; Loewen \& Philip, 2006) have broadened the definition of recasts to include varying degrees implicitness and explicitness. They posit that through the use of segmentation, stress and declarative intonation in recasts, the interlocutor can overtly state the existence of error and so switch the focus of interaction from meaning to form.

A commonly used indicator that learners have perceived a recast as corrective is whether they react to the recast in their next utterance (Lyster \& 
Ranta, 1997; Mackey et al., 2000). Lyster and Ranta (1997, p. 49) defined this learner reaction to feedback as uptake, and it is believed by many to be closely related to learner's perceptions about feedback at the time it is delivered (Mackey et al., 2000). Lyster and Ranta (1997, p. 49) stated that uptake could be classified as either repair or needs-repair. An utterance that contained a correct reformulation of the initial error was termed repair and an utterance that did not as needs-repair. Needs-repair could range from a simple acknowledgment to a partial reformulation. Lightbrown (1998, p. 193 in Egi, 2010) noted that repair, in particular, gave some reason to believe that the learner had "noticed the gap" (Schmidt \& Frota, 1986) between their erroneous utterance and the recast. An argument against the use of recasts is that they have often been found to result in lower levels of uptake than other feedback forms (Lyster \& Ranta, 1997; Mackey et al., 2000). However, there is some debate over whether uptake when used alone is an effective means of investigating learner noticing of recasts (Ellis et al., 2001).

Sheen (2007) took recast research in a new direction by investigating an experimental form of feedback combing recast with metalinguistic information. Sheen called this feedback type 'metalinguistic correction' and below is an example taken from her study (2007:307):

Student : There was a fox.

Fox was hungry.'

Teacher: The fox. You should use the definite article 'the' because you've already mentioned "fox".

Sheen (2007) found that in posttests measuring L2 gains the group receiving metalinguistic correction (in response to errors in article usage) outperformed the group receiving recasts, which also failed to perform significantly better than a control group. Sheen (2007) explained the positive effects of metalinguistic correction in terms of Schmidt's (1995, in Sheen, 2007) two levels of awareness; 'noticing' and 'understanding'. She pointed out that Schmidt (1995 in Sheen 2007) argued that 'noticing' was an important step towards acquisition while 'understanding' could result in deeper learning. Sheen (2007) concluded that the provision of a recast indicating the correct form, together with metalinguistic information was more effective than providing only a recast because it led to both the noticing and understanding of the underlying rule.

Despite the significant amount of literature on recasts and the potential of text-based SCMC (synchronous computed-mediated communication) in language learning, there have been only a few studies (Lai \& Zhao, 2006; Sachs \& Suh, 2007; Sauro, 2009) investigating recasts in a text-based SCMC environment. Interestingly, they observed a similar failure of learners to notice the corrective nature of recasts.

Lai and Zhao (2006) compared the capacity of text-based SCMC interaction and face-to-face interaction to promote learners' noticing of interactional feedback. In stimulated recall sessions, learners exhibited noticing of $45 \%$ negotiation of meaning episodes in text chat compared with $24 \%$ in face-to-face interaction. However, for recasts the opposite was true, with learners noticing only $10 \%$ of text chat recasts compared to $18 \%$ of face-to-face recasts. It must be noted, however, that the information about recasts provided by the findings was very limited. Lai and Zhao (2006) explained that the low level of noticing of text chat recasts may have resulted from the recasts being provided 3 to 4 turns after the learner's incorrect 
message.

Sachs and Suh (2007) investigated the efficacy of textually enhanced and textually unenhanced recasts of errors in their use of indirect reported speech in terms of learner awareness and L2 gains. The textual enhancement involved underling the matrix verbs and representing the back shifted verbs in bold face. Drawing on insights from Schmidt (1995 cited in Sachs in Suh, 2007), they investigated learner awareness of L2 form at the level of noticing and understanding. Schmidt (ibid:29) provided the following example to illustrate the difference:

'Awareness that a target language speaker says, on a particular occasion, 'He goes to a beach a lot,' is an example of noticing. Being aware that goes is a form of go inflected for number agreement is understanding.'

To measure awareness, Sachs and Suh (2007) used an introspective tool called the think-aloud technique. Verbalizations were coded according to three criteria for the presence of awareness: cognitive change, metaawareness and morphological awareness. Cognitive change was considered awareness at the level of noticing and the others awareness at the level of understanding. The study found that $100 \%$ of the textually enhanced and textually unenhanced groups verbalized awareness at the level of noticing. However, only $43 \%$ of the unenhanced group reported meta-awareness and none reported morphological awareness. On the other hand, $100 \%$ of the textually enhanced group reported metaawareness and 33\% reported morphological awareness.

Sachs and Suh (2007) found despite outperforming the unenhanced group in post-tests, the enhanced group were not able to identify appropriate uses of backshifting in context or produce it themselves with greater ability. Sachs and Suh (2007) noted that while the enhanced recasts successfully highlighted the verb forms, participants may have still failed to perceive them as corrective.

Sauro (2009) investigated the effects of test-based SCMC recasts and metalinguistic prompts on the development of learners' L2 knowledge of the English zero article with abstract uncountable nouns. The study found greater improvement in the immediate post-tests for the metalinguistic prompt group than the recast group.

Furthermore, $44 \%$ of metalinguistic prompts resulted in uptake compared to $21 \%$ of the recasts.

Sauro (2009) suggested the greater L2 gains and uptake associated with the metalinguistic prompts resulted from its overtly explicit corrective nature. She argued that the corrective intent of the recasts was less clear and so reduced opportunities for learners to "notice the gap" between recasts and their erroneous utterances. The recasts in the study were generally full and long and these characteristics have been shown in face-to-face recast studies to reduce the saliency of recasts to learners (Loewen \& Philip, 2006; Sheen, 2006). Also, at times there was a lack of adjacency between some of the recasts and the triggering erroneous utterance, an issue highlighted by Lai and Zhao (2006). Doughty and Long (2003:65) claimed learners needed to be able to hold both erroneous utterance and recast in their working memory to allow for comparison and noticing of any gap.

This research covers two research questions:

1. To what extent do hybrid text-based SCMC recasts of grammatical errors result in learner uptake? 
2. How do learners perceive hybrid text-based SCMC recasts of grammatical errors?

\section{METHOD}

This study was unique in the sense that the researcher and participants were located in different countries. As stated by Pellettieri (2000), text-based SCMC does not have the geographical constraints of face-to-face communication. Therefore, I decided that it would be interesting to carry out this research with participants located in a different country than myself.

While I was located in Malaysia, the participants of the study were parttime intermediate-level EFL students at my previous school, the British Council, Beirut. Participants were all female and aged between eighteen and thirty-two years old. They were university students, teachers, housewives, and office workers. Two were from Syria and eight were from Lebanon and all had Arabic as their first language. Facebook Messenger was used in nine of the text chat sessions and Google Talk in one.

The materials used in this study included two text chat tasks performed by participants and a native-speaking interlocutor, in this case the researcher. These text chat tasks were a spot-thedifference picture task adapted from Mackey et al. (2000), and a narrative picture task adapted from Sachs and Suh (2007). Tasks were primarily meaningfocused, had clearly defined outcomes and required learners to make use of their own linguistic resources (Ellis, 2003). The topic of the tasks was a holiday; selected in accordance to the topics the students had recently covered in class, participant interests and language levels. Two task types were used because previous research (Gass $e t$ al., 2005 in Egi, 2007) found that task type could affect the nature of interaction.

Each learner met the researcher online once in a 40-minute text chat session. The date and time of this text chat session was arranged via email exchange. The learners performed two dyadic text chat tasks with the researcher acting as interlocutor. Alongside performing the tasks, the interlocutor provided hybrid recasts of any grammatical errors made by the learner, as shown in the example below taken from the study.

Learner: $\mathrm{He}$ is wearing red T-shirt and shorts

Interlocutor: $\mathrm{He}$ is wearing a red T-shirt (indefinite article (a) + singular noun)

The hybrid recasts consisted of a recast of the error and metalinguistic information relating to the error, which was bracketed to differentiate it from the recast. To identify episodes of recasts and any subsequent uptake, chatscripts were saved and later analyzed.

Participants also completed a posttask questionnaire immediately after finishing the text chat task. Divided into two sections, the first consisted of five open-ended questions relating to learner noticing of the hybrid recasts; the second section included open-ended questions to elicit learner attitudes regarding the use of text chat in their language learning.

The chatscripts were analyzed for instances of hybrid recasts and subsequent uptake using a coding scheme, adapted from Lyster and Ranta's (2007) observational study of feedback and uptake in French immersion classes (Figure 1 contains a summary of both coding schemes; Figure 2 provides examples of each category of the coding scheme). 
The number and percentage of hybrid recasts that resulted in uptake and repair was then calculated for each participant and then for the study as a whole. This emulated the interaction analysis in previous recast studies (Lyster \& Ranta, 1997; Mackey et al., 2000).

Figure 1: Coding schemes

\begin{tabular}{lll}
\hline & Lyster and Ranta $(\mathbf{1 9 9 7 , \mathbf { p } \text { . 44) }}$ & This study \\
\hline Stage 1 & $\begin{array}{l}\text { Learner produces an erroneous } \\
\text { utterance }\end{array}$ & $\begin{array}{l}\text { Learner produces a grammatically incorrect } \\
\text { utterance }\end{array}$ \\
\hline Stage 2 & $\begin{array}{l}\text { Teacher provides a form of feedback } \\
\text { or continues with topic }\end{array}$ & $\begin{array}{l}\text { Interlocutor provides a hybrid recast of the } \\
\text { error }\end{array}$ \\
\hline Stage 3 & $\begin{array}{l}\text { If feedback provided, learner reacts to } \\
\text { feedback (uptake) or continues with } \\
\text { topic (no uptake); }\end{array}$ & $\begin{array}{l}\text { Learner reacts to hybrid recast (uptake) or } \\
\text { continues with topic (no uptake); }\end{array}$ \\
& $\begin{array}{l}\text { Uptake classified as repair or needs- } \\
\text { repair }\end{array}$ & Uptake classified as repair or needs-repair \\
\hline Stage 4 & $\begin{array}{l}\text { For repair, teacher continues topic or } \\
\text { provides reinforcement; }\end{array}$ & $\begin{array}{l}\text { For repair and needs-repair interlocutor } \\
\text { continues with topic }\end{array}$ \\
& $\begin{array}{l}\text { For needs-repair, teacher provides } \\
\text { follow-up feedback or continues with } \\
\text { topic }\end{array}$ & \\
\hline
\end{tabular}

Figure 2: Coding scheme: Examples from study

\begin{tabular}{lll}
\hline & \multicolumn{2}{c}{ Hybrid recast episodes } \\
\hline \multirow{2}{*}{ No uptake } & Learner & and he is wearing red shirt \\
\cline { 2 - 3 } & Interlocutor & wearing a red shirt (article (a) + singular noun) \\
\cline { 2 - 3 } & Learner & there are sofa and table \\
\cline { 2 - 3 } $\begin{array}{l}\text { Uptake } \\
\text { Repair }\end{array}$ & Learner & That clown is wearing colourful clothes \\
\cline { 2 - 3 } & Interlocutor & was wearing colourful clothes (use past continuous) \\
\hline Uptake & Learner & That clown was wearing colourful clothes \\
\cline { 2 - 3 } $\begin{array}{l}\text { Needs- } \\
\text { repair }\end{array}$ & Interlocutor & In front of desk there is open suit case. Do you have the same? \\
\cline { 2 - 3 } & Learner & There is an open suitcase (use article (a/an) with singular noun) \\
\hline
\end{tabular}

In addition to measuring uptake, the study analyzed participants' questionnaire responses for evidence of learner noticing, using the following three indicators:

1. A direct reference to the interlocutor correcting their mistake

2. Noticing the language feature that had been recast
3. Correctly stating the number of grammatical errors they had made*

( ${ }^{*}$ The study posited that if a learner's estimation of the number of grammatical mistakes made matched the number hybrid recasts they received, it could be concluded that they perceived every hybrid recast as corrective.) 


\section{RESULTS AND DISCUSSION \\ Hybrid recasts of grammatical errors and learner uptake}

Table 1: The frequency of hybrid recasts, uptake and repair

\begin{tabular}{cccc}
\hline Participant & $\begin{array}{l}\text { Number of hybrid } \\
\text { recast episodes }\end{array}$ & $\begin{array}{l}\text { Subsequent uptake }(\% \\
\text { of hybrid recasts) }\end{array}$ & $\begin{array}{l}\text { Subsequent repair (\% of } \\
\text { hybrid recasts) }\end{array}$ \\
\hline 1 & 4 & $3(75 \%)$ & 0 \\
\hline 2 & 6 & $3(50 \%)$ & 0 \\
\hline 3 & 9 & 0 & 0 \\
\hline 4 & 6 & $6(100 \%)$ & $5(83 \%)$ \\
\hline 5 & 5 & $2(40 \%)$ & 0 \\
\hline 6 & 4 & $4(100 \%)$ & 0 \\
\hline 7 & 8 & $8(100 \%)$ & $1(25 \%)$ \\
\hline 8 & 4 & $2(50 \%)$ & 0 \\
\hline 9 & 6 & $5(83.3 \%)$ & 0 \\
\hline 10 & 1 & $1(100 \%)$ & $\mathbf{9 ( 1 7 \% )}$ \\
\hline Total & $\mathbf{5 3}$ & $34(\mathbf{6 4 \% )}$ & \\
\hline
\end{tabular}

The frequency of hybrid recasts and subsequent uptake and repair is presented in Table 1 above. Participants received between four and nine hybrid recasts during the text chat tasks, with the exception of participant 10, who received only one. Nine participants reacted to hybrid recasts with uptake. The lowest level of uptake among these nine was $40 \%$ and the highest was $100 \%$, achieved by four participants. Only three participants responded to hybrid recasts with repair. $47 \%$ of hybrid recasts were followed by needs-repair and $17 \%$ by repair. Therefore, $64 \%$ resulted in some form of uptake.

\section{Learners' perception of hybrid recasts of grammatical errors}

All participants directly mentioned at some point in the questionnaire that the interlocutor had corrected their mistakes during the text chat tasks. Four participants referred to this twice.

Although no limit was set on the number of features participants could report noticing, seven participants responded with only one answer and one participant did not respond. In addition, four participants indicated a number of mistakes that exactly matched the number of hybrid recasts they received. Two participants provided answers that roughly matched. Of the four that provided a number that did not match, one had misinterpreted the question.

Furthermore, four participants made some reference to their inability to use grammar accurately and a need to improve their English. Two participants similarly mentioned a failure to use grammar correctly. This is further evidence that participants noticed their non-target use of English grammar, which implies that they perceived hybrid recasts to be negative evidence.

\section{Hybrid recasts of grammatical errors and learner uptake}

The data collected from the analysis of chatscripts of the text chat tasks indicated that almost two thirds of the hybrid recasts provided resulted in uptake. Table 2 shows the percentage of hybrid recasts that resulted in uptake, repair and needs-repair compared with feedback types in previous studies. 
Table 2: Uptake following hybrid recasts, recasts and metalinguistic feedback

\begin{tabular}{|c|c|c|c|c|c|}
\hline \multirow[t]{2}{*}{ Study } & \multirow[t]{2}{*}{ Setting } & \multirow[t]{2}{*}{ Feedback type } & \multicolumn{3}{|c|}{$\begin{array}{l}\% \text { of student turns following the } \\
\text { feedback that contained; }\end{array}$} \\
\hline & & & Uptake & Repair & Needs-repair \\
\hline $\begin{array}{l}\text { This study } \\
\text { (2013) }\end{array}$ & $\begin{array}{l}\text { Text-based } \\
\text { SCMC }\end{array}$ & Hybrid recast & 64 & 17 & 47 \\
\hline \multirow{2}{*}{$\begin{array}{l}\text { Lyster and } \\
\text { Ranta (1997) }\end{array}$} & \multirow[t]{2}{*}{ Face-to-face } & Recast & 31 & 18 & 13 \\
\hline & & Metalinguistic feedback & 86 & 45 & 41 \\
\hline \multirow{2}{*}{$\begin{array}{l}\text { Panova and } \\
\text { Lyster (2002) }\end{array}$} & \multirow[t]{2}{*}{ Face-to-face } & Recast & 40 & 13 & 27 \\
\hline & & Metalinguistic feedback & 71 & 29 & 42 \\
\hline \multirow[t]{2}{*}{ Sauro (2009) } & \multirow[t]{2}{*}{$\begin{array}{l}\text { Text-based } \\
\text { SCMC }\end{array}$} & Recast & 21 & $\begin{array}{l}\text { Not } \\
\text { available } \\
\text { (N/A) }\end{array}$ & $\mathrm{N} / \mathrm{A}$ \\
\hline & & Metalinguistic prompt & 44 & $\mathrm{~N} / \mathrm{A}$ & $\mathrm{N} / \mathrm{A}$ \\
\hline
\end{tabular}

As Table 2 highlights, the level of uptake after hybrid recasts (64\%) seems high when looking at the level of uptake that followed recasts in previous face-toface and text-based SCMC study. Only between $31 \%-40 \%$ of recasts in face-toface studies by Lyster and Ranta (1997), and Panova and Lyster (2002) were followed by uptake. This figure was even lower in the text-based SCMC study by Sauro (2009), which also experienced relatively low levels of uptake after metalinguistic prompts. Interestingly, the hybrid recasts led to a level of uptake more usually associated with metalinguistic feedback.

Sauro (2009) explained that the low level of uptake identified in her study might have resulted from a lack of adjacency between the learner error and recast. In this study, $29 \%$ of the hybrid recasts were not provided in the turn immediately following the erroneous utterance, as highlighted in Excerpt $A$. However, this did not seem to have an adverse effect on the level of uptake.

Excerpt A

Participant 9: This looks like a hotel room, there are two beds which are not used yet Participant 9: And something on the bed Interlocutor: which haven't been used yet (use present perfect)

Participant 9: Thank you!

The relatively high level of uptake that followed hybrid recasts can be seen to result from learners more clearly perceiving them to be negative evidence. The low level of uptake usually associated with recasts has been explained by learners sometimes interpreting recasts as performing functions other than feedback, such as acknowledging (Nicholas et al., 2000). In such cases, recasts are perceived to be positive evidence. The high level of uptake following hybrid recasts indicates that while the recast may or may not be perceived as negative evidence, the metalinguistic information most likely is. Therefore, the level of uptake is more similar to that associated with metalinguistic feedback, as shown in Table 2.

Another possible reason for the high level of uptake is that hybrid recasts are a significantly more explicit form of feedback than recasts. Long (1996 in Long et al., 1998) argued that recasts were implicit because they implied errors whose focus was on meaning rather than form. However, hybrid 
ENGLISH REVIEW: Journal of English Education Vol. 5, Issue 1, December 2016

recasts explicitly draw learners' attention to the existence of an error. Studies have repeatedly shown that learners are more likely to recast to explicit forms of feedback, such as metalinguistic feedback, as highlighted in Table 2.
ISSN 2301-7554

https://journal.uniku.ac.id/index.php/ERJEE

Excerpt B

Interlocutor: brown curtains (plural form)

Participant 1: yes thanks

The text-based SCMC setting of this study may have had an effect on the level of repair. In his text-based SCMC study of negotiated interaction, uptake and lexical acquisition, Smith (2005) found that only $11 \%$ of negotiated focus on form episodes resulted in repair. He argued that the low level of successful uptake or repair in text chat was due to the visual representation of the language, the pressure to respond quickly and the redundancy of retyping the recast. Smith (2005) reported similar lexical gains from learners, independent of whether they produced repair, needsrepair or no uptake.

\section{Learners' perception of hybrid recasts of grammatical errors}

The qualitative data collected from the post-task questionnaires would seem to confirm that learners perceived the corrective nature of hybrid recasts of their grammatical errors. Interestingly, despite every participant clearly reporting that recasts were corrective, only three participants provided uptake after every hybrid recast. In fact, one participant did not provide any uptake at all, yet still claimed to have noticed that they were corrective in the questionnaire. This contrasts with the findings of Egi's (2010) and Mackey et al's (2000) face-to-face studies. They found that when learners did not follow recasts with uptake, they
While the overall level of uptake for hybrid recasts was quite high, only $17 \%$ resulted in repair. The majority of uptake was needs-repair and took the form of acknowledgement (Lyster \& Ranta, 1997, p. 50) or recognize (Ellis et al., 2001, p. 298), as shown in the Excerpt $B$. were unlikely to perceive recasts as corrective in stimulated recall. Also, Egi (2010) observed that learners who produced repair were much more likely to accurately perceive recasts than those producing needs-repair. This study found otherwise, with accurate perception of recasts despite low levels of repair.

In response to the findings, two claims could possibly be made about the use of uptake as an indicator of learner noticing in text-based SCMC. The first is that as Smith (2005) argued needs-repair is an equally good indicator that a learner has accurately perceived a textbased recast as repair. The second is that while uptake may indicate that the learner has correctly perceived the corrective force of the recast, an absence of uptake cannot be interpreted as evidence that the learner has not perceived the recast. As stated by Smith (2005) uptake may be precluded by features of text chat, such as visual saliency and pressure to type responses quickly. Ellis et al. (2001) argued that uptake could also be precluded by discourse considerations in face-to-face interaction.

A possible explanation as to why all participants successfully perceived the hybrid recasts to be negative evidence in the post task questionnaire despite not always producing uptake is the visual and enduring quality of text chat (Sauro, 2009). 
Because the chatscripts were saved on the learners' computer screens, they were able to revisit them post task while completing the questionnaire. Therefore, while they may not have noticed that the hybrid recasts were corrective during the interaction, and so produced no uptake, a second or third reading may have facilitated noticing of their corrective nature. This revisiting of the hybrid recast episodes also provided learners with further opportunities for Schmidt's (1995) noticing of the gap between their interlanguage and the target form. The likelihood of this noticing occurring was potentially increased because learners did not need to hold both the erroneous utterance and recast in the working memory for comparison as in face-to-face interaction (Williams, 2005 in Sauro, 2009).

Another finding from this study was that four participants used metalinguistic terminology to report what they had noticed about English during the text chat tasks. In Sachs and Suh's (2007) study, this was coded as morphological awareness and considered to indicate awareness of L2, which Schmidt (1995 in Sachs \& Suh, 2007) classified as at the level of understanding. In Sachs and Suh's study, $33 \%$ of participants who received textually enhanced recasts reported morphological awareness in think-aloud vocalizations and $38 \%$ reported sensing that the interlocutor had been focusing on the correct use of verb tenses in the briefing questionnaire. Therefore, the levels of morphological awareness reported by learners receiving textually enhanced and hybrid recasts was similar. Sheen (2007) explained the greater L2 gains attributed to his metalinguistic correction, the feedback form that hybrid recasts were adapted from, in terms of Schmidt's (1995, in Sheen, 2007) two levels of awareness; noticing and understanding. As noted by Sheen, Schmidt (1995) argued that 'noticing' was an important step towards acquisition while 'understanding' could result in deeper learning. Sheen (2007) concluded that the provision of the correct form and metalinguistic feedback was effective because it led to both the noticing and understanding of the underlying rule. This provides a possible explanation for the morphological awareness reported by three learners.

\section{CONCLUSION}

This study used two sources of data to investigate whether learners carrying out text chat tasks perceived hybrid recasts of grammatical errors to be corrective. Chatscripts of the tasks were analyzed to identify the distribution of hybrid recasts and subsequent uptake and a post-task questionnaire yielded qualitative data on learner perceptions of hybrid recasts. Both sources revealed that learners generally perceived the hybrid recasts to be corrective. When compared with findings from previous face-to-face (Lyster \& Ranta, 1997; Mackey et al., 2000) and text chat (Lai \& Zhao, 2006; Sauro, 2009) recast studies, results indicate that the corrective force of hybrid recasts might be clearer than traditional recasts. As such, further study into forms of text chat feedback that combine recast with metalinguistic information is warranted.

\section{REFERENCES}

Bao, M., Egi, T \& Han, Y (2011). Classroom study on noticing and recast features: Capturing learner noticing with uptake and stimulated recall. System, 39, 215-228.

Doughty, C., \& Long, M, (2003). Optimal psycholinguistic environments for distance foreign language learning. 
ENGLISH REVIEW: Journal of English Education Vol. 5, Issue 1, December 2016

Language Learning and Technology, 7(3), 50-80.

Doughty, C., \& V, E. (1998). Communicative focus on form. In C. Doughty \&J. Williams (Eds.), Focus on form in classroom second language acquisition, (114-138). Cambridge: Cambridge University Press.

Egi, T, (2007). Recasts, learner's interpretations, and L2 development. In Mackey, A. (Ed.) (2007).

Conversational interaction in second language acquisition. Oxford: Oxford University Press

Egi, T, (2010). Uptake, Modified Output, and Learner Perceptions of Recasts: Learner Responses as Language Awareness. The Modern Language Journal, 94, 1-21.

Ellis, R, (2003). Task based language learning and teaching. Oxford: Oxford University Press.

Ellis, R., Basturkmen, H., \& Loewen, S. (2001). Learner Uptake in Communicative ESL Lessons. Language Learning, 51(2), 281-318.

Ellis, R., \& Sheen, Y. (2006). Re-examining the role of recasts in second language acquisition. Studies in second language acquisition, 28(4), 575-600. Cambridge University Press.

Kung, S, (2004). Synchronous electronic discussions in EFL reading class. ELT Journal, 58(2), 164-173.

Lai, C., \& Zhao, Y. (2006). Noticing and textbased chat. Language Learning and Technology, 10(3), 102-120.

Loewen, S., \& Philip, J. (2006). Recasts in the adult L2 classroom: characteristics, explicitness and effectiveness. The Modern Language Journal, 90(4), 536556.

Long, M. (1996). The role of the linguistic environment in second language acquisition. In Ritchie, W.R, \& Bhatia, T.J., (Eds.) Handbook of Second Language Acquisition. Academic Press, 413-468.

Long, M., Inagaki, S., \& Ortega, L. (1998). The role of implicit negative feedback in SLA: Models and recasts in Japanese and Spanish. The Modern Language
ISSN 2301-7554

https://journal.uniku.ac.id/index.php/ERJEE

Journal, 82, 357-371.

Lyster, R. (1998). Negotiation of form, recasts, and explicit correction in relation to error types and learner repair in immersion classrooms. Language Learning, 48(2), 183-218.

Lyster, R., \& Ranta, L. (1997). Corrective feedback and learner uptake, negotiation of form in communicative classrooms. Studies in Second Language Acquisition, 20, 36-66. Cambridge University Press.

Lyster, R., \& Mori, H. (2006). Interactional feedback and instructional counterbalance. Studies in Second Language Acquisition, 28, 269-300, Cambridge University Press.

Mackey, A., Gass, S., \& Mcdonough, K. (2000). How do learners perceive feedback? Studies in Second Language Acquisition, 22, 471-497. Cambridge University Press.

Nicholas, H., Lightbrown, P., \& Spada, N. (2001). Recasts as feedback to language learners. Language Learning, 51, 719-758.

Oliver, R. (1995). Negative feedback in child NS-NNS conversation. Studies in Second Language Acquisition, 17, 459481. Cambridge University Press.

Pellettieri, J. (2000). Negotiation in cyberspace: The role of chatting in the development of grammatical competence. In Warschauer, M., \& Kern. R. (2000). Network-based Language Teaching: Concepts and Practice, (59-86), $3^{\text {rd }}$ Printing. Cambridge University Press.

Sachs, R., \& Suh, B. (2007). Textually enhanced recasts, learner awareness, and L2 outcomes in synchronous computer-mediated interaction. In Mackey, A. (2007). Conversational interaction in second language acquisition, (197-228), Oxford University Press.

Sauro, S. (2009). Computer-mediated corrective feedback and the development of L2 grammar. Language Learning and Technology, 13(1), 96-120.

Schmidt, R. (1990). The role of consciousness in second language learning. Applied linguistics, 11, 129-58. 
Mark J. Oliver

Noticing Hybrid Recasts in Text Chat

Schmidt, R., \& Frota, S. (1986). Developing basic conversational ability in a second language: a case study of an adult learner of Portuguese. In Day (Ed.). 1986

Sheen, Y. (2006). Exploring the relationship between characteristics of recasts and learner uptake, Language Teaching Research, 10(4), 361-392.

Sheen, Y. (2007). Corrective feedback, individual differences, and acquisition of articles. In Mackey, A. (2007).

Conversational interaction in second language acquisition, (229-248). Oxford: Oxford University Press.

Simpson, J. (2002). Computer-mediated communication. ELT Journal, 56(4),
414-415. Oxford: Oxford University Press.

Smith, B. (2004). Computer-mediated negotiated interaction and lexical acquisition. Studies in Second Language Acquisition, 26, 365-398. Cambridge University Press.

Smith, B. (2005). The relationship between negotiated interaction, learner uptake, and lexical acquisition in task-based computer-mediated communication. TESOL Quarterly, 39(1), 33-58.

Smith, B., \& Sauro, S. (2009). Interruptions in chat. Computer Assisted Language Learning, 22(3), 229-247. 